\title{
Levantamento de ocorrências fósseis nas pedreiras de calcário do Subgrupo Irati no estado de São Paulo, Brasil
}

\author{
Fresia Ricardi-Branco ${ }^{1}$,Edgar Taveiros de Caires $^{2}$ \& Adalene Moreira Silva ${ }^{3}$
}

\begin{abstract}
Resumo O principal objetivo da presente pesquisa foi contribuir para a atualização dos dados paleontológicos do Subgrupo Irati no Estado de São Paulo, por meio do levantamento dos fósseis existentes nas pedreiras ativas e sua comparação com as referências encontradas na literatura. Foram visitadas dezoito pedreiras ativas e em todas foi verificada a presença abundante de fósseis. Para otimizar a comparação e distribuição dos fósseis estudados, os dados obtidos foram incorporados em ambiente de sistema de informações geográficas (SIG). Dessa forma, foram registradas duas novas ocorrências de vegetais fósseis em Saltinho e Itapetininga. Os fósseis de vertebrados (mesossaurídeos) foram frequentemente observados em todas as pedreiras visitadas e novas ocorrências são aqui indicadas para Cesário Lange, Pereiras, Saltinho e Tietê. Por último, foi verificada a presença de coquinas compostas por carapaças de crustáceos nas pedreiras de Angatuba, Cesário Lange, Itapetininga, Ipeúna, Limeira, Pereiras, Saltinho e Tietê, bem como estromatólitos gigantes em Santa Rosa de Viterbo, muitas vezes com ossos de messosaurídeos intercalados. Foi também comprovado que na maioria das frentes de lavra das pedreiras anteriormente estudadas e hoje desativadas, a coleta de fósseis é pouco representativa, uma vez que as frentes de lavra encontram-se muito deterioradas. Contudo, após a presente atualização das informações acerca da localização das pedreiras ativas e do seu conteúdo fossilífero, será mais simples a realização de novos estudos.
\end{abstract}

Palavras-chave: Mesossaurídeos, Irati, Permiano, Bacia do Paraná.

\begin{abstract}
Fossil record of carbonate quarries from Irati Subgroup in the state of São Paulo, Brazil. The main focus of this work was to contribute for the paleontological updating of Irati Subgroup in the state of São Paulo, through the searching of extent fossils at active quarries and their comparison to the ones found in literature references. Hence, eighteen active quarries were visited and in all of them many fossils were found. In order to optimize the comparison and distribution of the studied fossils, the data was added to geographic information system (GIS). It was found two new localities of fossil plants in Saltinho and Itapetininga. The most abundant vertebrate fossil found in all visited quarries were mesosauridean bones, new localities were described to Cesário Lange, Pereiras, Saltinho and Tietê. Finally, abundant coquinas composed by shellfish shells were found in Angatuba, Cesário Lange, Itapetininga, Ipeúna, Limeira, Pereiras, Saltinho and Tietê quarries. As well as giant stromatolites in Santa Rosa de Viterbo interbeded with mesosauridean bones. It was also noticed that most of the extraction faces of quarries studied before, and nowadays inactivated, the fossil collect is less productive once the extraction faces found are damaged. However, with the present work the information presented about the active quarry locations and their fossiliferous contents lead to new researches.
\end{abstract}

Keywords: Mesosaurs, Irati, Permian, Paraná Basin.

INTRODUÇÃO Os fósseis são instrumentos fundamentais para a compreensão do aparecimento e evolução da vida no nosso planeta durante sua longa história geológica, uma vez que fornecem informações acerca do ambiente no qual habitaram (Carvalho 2000), sua ecologia e época, sendo possível estabelecer idades relativas e relações estratigráficas, como é o caso do Subgrupo Irati (sensu Hachiro et al. 1993), objeto de estudo do presente trabalho. Essa unidade, no Estado de São Paulo, apresenta considerável distribuição geográfica, o que facilita a correlação entre localidades com base nas suas características litológicas e paleontológicas.

Como conseqüência do Subgrupo Irati apresentar camadas ricas em bens minerais, sua faixa aflorante vem sendo explorada continuamente desde o século $\mathrm{XX}$, motivo pelo qual os afloramentos de calcário ("banco dolomítico") correspondem com a localização das principais pedreiras, em especial do Estado de São Paulo. Nas frentes de lavras das pedreiras há a oportunidade de se recolher dados paleontológicos, que auxiliam no estudo e compreensão dos aspectos geológicos das formações Taquaral e Assistência, por meio de correlações

1- Departamento de Geologia e Recursos Minerais, Instituto de Geociências, Universidade Estadual de Campinas, Campinas, (SP), Brasil.

E-mail: fresia@ige.unicamp.br

2 - Companhia de Pesquisa de Recursos Minerais, GEREMI - Gerência de Recursos Minerais, São Paulo, (SP), Brasil.

E-mail: edcaires@gmail.com

3 - Instituto de Geociências, Universidade de Brasília, Brasília, (DF), Brasil. E-mail: adalene@unb.br 
bioestratigráficas e paleoambientais, entre outras.

No que diz respeito à coleta de amostras (fósseis) para estudo, as pedreiras representam importantes fontes de dados, uma vez que o trabalho de exploração expõe grandes frentes de rochas e estratos que ainda não sofreram a ação do intemperismo e erosão, como ocorre em exposições de taludes de estradas, por exemplo. Dessa forma, o principal objetivo do presente trabalho foi contribuir para a atualização dos dados paleontológicos do Subgrupo Irati no Estado de São Paulo por meio do levantamento dos fósseis existentes nas pedreiras ativas e sua comparação com as referências encontradas na literatura. Para otimizar esta comparação e distribuição dos fósseis estudados dentro do Subgrupo Irati, os dados obtidos foram incorporados em ambiente de sistema de informações geográficas (SIG).

Vale lembrar que algumas pedreiras passaram por processos de desativação e voltaram a ser exploradas em épocas mais recentes com outro nome/razão social (e.g. Pedreira do Mondini arrendada para Pedreira Bonança, em Ipeúna; Pedreiras Moura, Parcker e Maluf arrendadas para Pedreira Vitti; Pedreira Cruzeiro e Itaitê, mudaram registro para PH7, em Santa Rosa do Viterbo; Pedreira Itapetininga, mudou para Calcário Itapê no transcurso de 2005, em Itapetininga; etc.), mas o controle desse tipo de informação é escassa nos órgãos governamentais e, somado com a inexistência de dados referentes às coordenadas das áreas de extração, tornam extremamente difícil o reconhecimento e a determinação das ocorrências e re-ocorrências, fossilíferas.

Sendo assim, o presente trabalho tem a intenção de fornecer um panorama geral sobre novas ocorrências, a partir da análise dos dados, mas pode ocorrer sobreposição de referências, dada a vacuidade das informações técnicas, pelos motivos supracitados.

Localização da área de estudo O Subgrupo Irati (Hachiro et al. 1993), unidade basal do Grupo Passa Dois aflora, no Estado de São Paulo, em faixas estreitas e alongadas, com extensão de alguns metros até quase uma dezena de quilômetros. A figura 1 ilustra a área de estudo, indicando a localização das pedreiras visitadas. Os pontos indicados correspondem a grande parte da faixa aflorante do Grupo Passa Dois no Estado de São Paulo.

Essa unidade ocorre no interior da feição geomorfológica conhecida como Depressão Periférica Paulista e sua configuração se manifesta por meio de uma inflexão, na altura do município de Itapetininga, segundo um ângulo aproximado de $110^{\circ}$. Nesta região, a partir de um ponto comum, separam-se duas estreitas faixas de

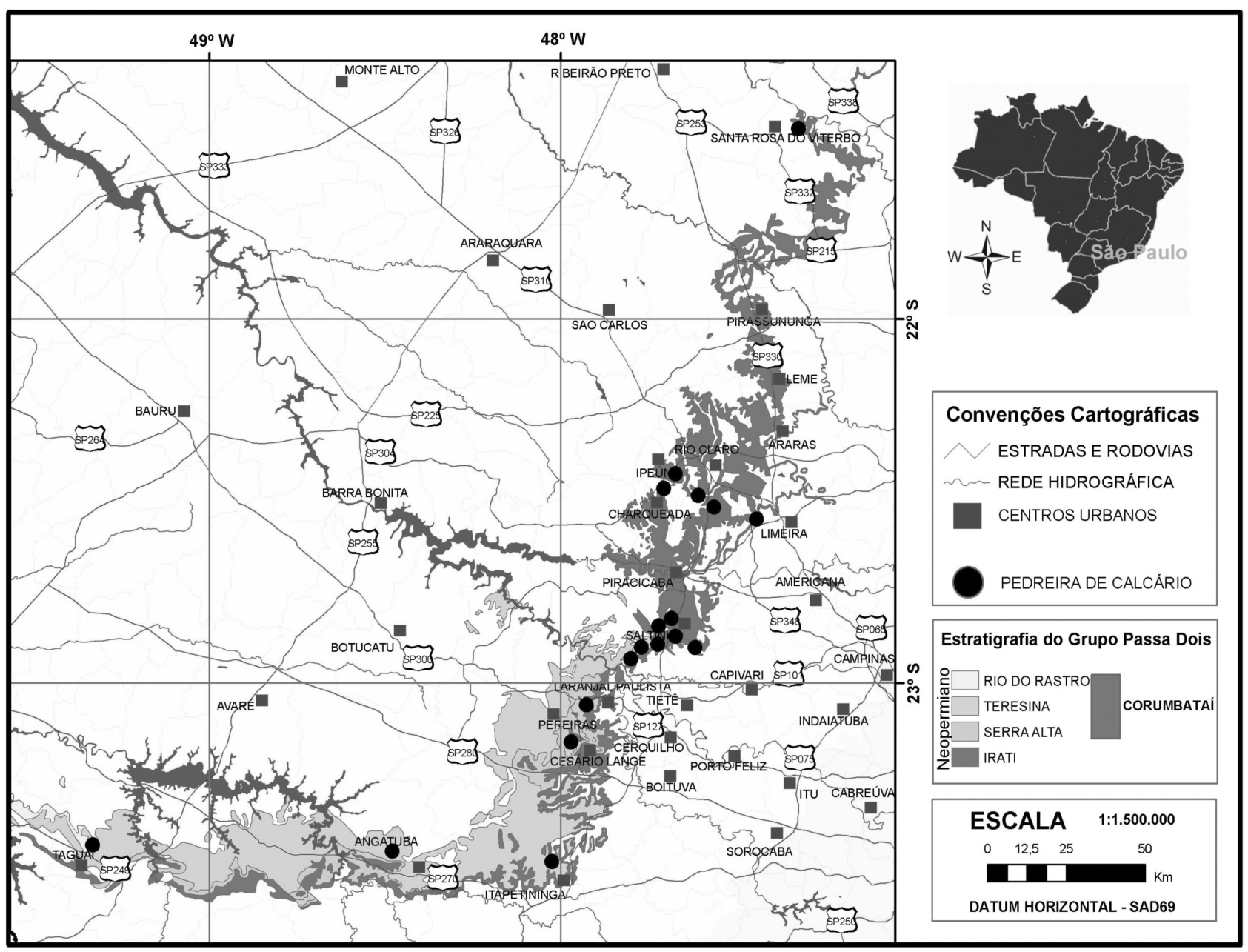

Figura 1 - Área estudo, indicando a localização das pedreiras visitadas. 
afloramentos: uma rumo ao NE até o município de Santa Rosa do Viterbo, com extensão aproximada de 240 quilômetros, e outra se estendendo por cerca de 160 quilômetros na direção E-W que atinge as margens do Reservatório de Xavantes, nos arredores da cidade de Fartura, na divisa com o Estado do Paraná (Hachiro 1991).

Ao longo dessa faixa onde ocorrem as rochas sedimentares do Subgrupo Irati encontram-se instaladas as empresas mineradoras que exploram o calcário (calcítico/dolomítico) com fins agrícolas, correspondendo suas frentes de lavras às melhores exposições e, consequentemente, de disposição de estruturas sedimentares e exemplares fósseis melhor conservados (Fig. 1). A tabela 1 apresenta os principais municípios que abrigam as áreas de extração e lavra dessas mineradoras.

\section{CONTEXTO GEOLÓGICO E PALEONTOLÓGI-}

CO O contexto litoestratigráfico da área estudada ainda é palco de controvérsias. Neste trabalho, foi adotada a proposta de Hachiro et al. (1993), que se considera perfeitamente aplicável para o Estado de São Paulo.

O Subgrupo Irati, unidade basal do Grupo Passa Dois, foi depositado em condições de mar restrito, progressivamente mais salino da base para o topo. Essa unidade é caracterizada por uma faciologia bastante complexa, com folhelho, folhelho betuminoso, arenito, marga, carbonato e anidrita, indicativos de uma geometria de bacia igualmente complexa, em que se configuravam ambientes de golfos e baías de profundidades e salinidades extremamente variáveis (Hachiro et al. (1993).

O Subgrupo Irati se estende por uma área de aproximadamente um milhão de quilômetros quadrados, abrangendo, no Brasil, os estados de Mato Grosso do Sul, Mato Grosso, Goiás, São Paulo, Paraná, Santa Catarina e Rio Grande do Sul e, na Bacia do ChacoParaná, parte da Argentina, Paraguai e Uruguai. No Estado de São Paulo é subdivido estratigraficamente nas formações Taquaral e Assistência, sendo esta última composta pelos membros Morro do Alto e Ipeúna (Hachiro 1996), como mostra a tabela 2.

Atualmente, o Subgrupo Irati designa um pacote de rochas que pode alcançar a espessura de aproximadamente 70 metros de sedimentos, nas porções centrais da bacia, sendo que a seqüência estratigráfica pode ser reconhecida com clareza no Estado de São Paulo.

MATERIAIS E MÉTODOS Para que o projeto tivesse o êxito desejado buscou-se acessar todas as bases digitais disponíveis (DNPM 2005) que compuseram um banco de dados georreferenciados. Estas informações foram, posteriormente, processadas em ambiente SIG utilizando o software ArcGis 9.x. São elas: mapa Rodoviário do Estado de São Paulo (edição 2004) (DER - SP 2004), na escala 1:1.000.000 e o mapa geológico do Estado de São Paulo, na escala 1:1.000.000 (CPRM 2005). Utilizou-se ainda os dados altimétricos gerados pela "Shuttle Radar Topography Mission" (SRTM), por meio da tecnologia de interferometria SAR (InSAR) coletados no ano de 2000 e para o georeferenciamento das pedreiras durante as visitas foi utilizado um aparelho de GPS (E-Trex/Garmin) e uma de câmera digital para registros dos fósseis e pedreiras. Com base nos dados MDE foi gerado um mapa que mostra a faixa aflorante da unidade em estudo.

O trabalho teve como ponto inicial uma extensa pesquisa bibliográfica, onde foram analisados

Tabela 1 - Pedreiras visitadas, no estado de São Paulo. Minerações instaladas (DNPM, 2005). Algumas mineradoras têm unidades de beneficiamento em Itapeva (Mineração Gobbo) e Piracicaba (Mineração Vitti).

\begin{tabular}{l|l}
\hline \multicolumn{1}{c|}{ Município } & \multicolumn{1}{c}{ Minerações de Calcário agrícola } \\
\hline Angatuba & Mineração Cinco Estrelas [inativa] \\
\hline Cesário Lange & RochaFértil Indústria e Comércio Calcário \\
\hline Ipeúna & Calcário Bonança e Mineração Carvalho [inativa] \\
\hline Itapetininga & Calcário Itapê \\
\hline Limeira & Calcário Cruzeiro \\
\hline Pereiras & Calcário Cruzeiro \\
\hline Rio Claro & Partecal Partezani e Mineração de Calcário Vitti 2 (Assistência - inativa) \\
\hline Saltinho & $\begin{array}{l}\text { Mineração de Calcário Vitti 1, Mineração SoloFértil [inativa], Mineração Amaral Machado, } \\
\text { Mineração Bernardino \& CIA, Mineração de Calcário Calgi e Calcário Diamante }\end{array}$ \\
\hline Santa Rosa do Viterbo & PH7 Mineração de Calcário \\
\hline Taguaí & \begin{tabular}{l} 
Mineração Gobbo \\
\hline Tietê
\end{tabular} \\
\hline
\end{tabular}


Tabela 2 - Subdivisão litoestratigráfica e Zoneamento biestratigráfico do Subgrupo Irati para o Estado de São Paulo. Fonte Hachiro 1996 e Mezzalira 1980, 1989 e $2000^{(1)}$ Assembléias fósseis de invertebrados (e.g. crustáceos); (2) Assembléias fósseis de vertebrados (e.g. mesossaurídeos).

\begin{tabular}{|c|c|c|c|}
\hline \multirow{8}{*}{$\begin{array}{l}\text { Subgrupo } \\
\text { Irati }\end{array}$} & \multirow{7}{*}{$\begin{array}{l}\text { Formação } \\
\text { Assistência }\end{array}$} & \multirow{3}{*}{ Membro Ipeúna } & Ritmitos Superiores $^{(1)(2)}$ \\
\hline & & & Ritmitos delgados regulares ${ }^{(1)(2)}$ \\
\hline & & & Camadas Bairrinho ${ }^{(1)(2)}$ \\
\hline & & \multirow{4}{*}{$\begin{array}{l}\text { Membro Morro do } \\
\text { Alto }\end{array}$} & Camadas Laje Azul ${ }^{(1)}$ \\
\hline & & & Ritmitos inferiores ${ }^{(1)}$ \\
\hline & & & Camadas Evaporíticas \\
\hline & & & Camadas de folhelhos Pirobetuminosos \\
\hline & \multicolumn{3}{|c|}{ Formação Taquaral $^{(1)}$} \\
\hline
\end{tabular}

dados referentes às pedreiras do Estado de São Paulo localizadas nas áreas pertencentes ao Subgrupo Irati. Procurou-se conhecer o porte, a situação das pedreiras e também o tipo de extração que vem sendo realizada (DNPM 2005). A partir dessa compilação inicial, foram levantadas todas as pedreiras já mencionadas e visitadas em trabalhos anteriores e aquelas onde nenhuma pesquisa foi elaborada. Em seguida foram realizados trabalhos de campo, tanto nas pedreiras já estudadas quanto nas pedreiras ainda não pesquisadas, cujos dados foram reunidos com os demais armazenados, formando o conjunto total das informações a serem processadas e analisadas em ambiente SIG.

No total realizaram-se 12 (doze) atividades de campo entre os anos 2004 e 2005, englobando todas as 18 (dezoito) pedreiras em atividade. Para efeito de localização e georreferenciamento das mesmas, foi utilizado um aparelho de GPS (E-Trex/Garmin), adotando os sistemas: UTM (para distâncias menores - e.g. detalhes dos cortes das frentes de lavra para medição da extensão e formato da cava) e geodésico (para distâncias maiores - maior parte dos casos). O datum adotado foi o SAD69 (South American Datum - 1969), tanto na aquisição dos dados por GPS em campo quanto no processamento em ambiente SIG, para a geração dos mapas temáticos. O procedimento no campo foi sistematizado da mesma forma, para todas as pedreiras visitadas. Assim foi, realizado um estudo de todo o perfil aflorante, buscando reconhecer as subunidades do Subgrupo Irati, fácies, possíveis contatos com as formações adjacentes, bem como um exaustivo registro fotográfico. Foram procurados no perfil fósseis in situ, da mesma forma que nas pilhas de desmonte e rejeito, sendo que em ambas as situações foi possível a coleta de exemplares fósseis.

No Laboratório de Paleohidrogeologia/DGRN/ IG/UNICAMP os exemplares coletados foram limpos e fotografados, bem como realizada a catalogação na Coleção Científica de Paleontologia (CP). No total foram obtidos 56 exemplares.
O mapa-base foi confeccionado através da ortorretificação e georreferenciamento do mapa Rodoviário do Estado de São Paulo. Para isso foi usado o programa ErMapper 6.4 (ERMAPPER), onde se empregou o ajuste do mapa ao sistema de coordenadas mais adequado, levando em consideração parâmetros como DATUM e PROJEÇÃO, além de estabelecer um controle sobre os erros de georreferenciamento. Como produto foi gerado um arquivo no formato [GEOTIFF], que posteriormente foi vetorizado no AutoCAD 2006 (AutoDesk) para poder selecionar as rodovias e estradas, principais rios e outros temas relevantes ao projeto. A escolha do uso de coordenadas geográficas para a confecção do Mapa-Base foi devido à escala de trabalho, uma vez que foi proposta a digitalização básica para todo o estado, visando manter aberta a possibilidade futura de expansão da área e inserção de novos dados. Portanto, para as áreas de ocorrência das rochas do Subgrupo Irati, foram digitalizadas as rodovias e as estradas secundárias de acesso às pedreiras e, para o restante do estado, foram digitalizadas somente as principais rodovias e o limite interestadual.

De forma simultânea às atividades acima descritas, foi realizado um trabalho de processamento dos dados do sensor remoto SRTM para as áreas compreendidas no Subgrupo Irati no Estado de São Paulo, como o uso do programa ENVI 4.1 (Sulsoft). Adquiridas as informações, foi efetuada a análise integrada das mesmas, lançando mão do uso de programas (SIGs) voltados para a análise espacial de dados, como o ArcGIS 9.0 (ESRI), para a geração dos mapas temáticos, a saber: mapa-base de pontos (localização das pedreiras, estradas e municípios); mapa geológico (contexto geológico do Subgrupo Irati e do Grupo Passa Dois na Bacia do Paraná, dentro do território do Estado de São Paulo); mosaico do modelo digital de terreno (gerado a partir dos dados da SRTM) para área estudada, integrado ao mapa geológico.

RESULTADOS Como todas as pedreiras exploravam na época da pesquisa, o bem mineral calcário 
(calcítico/dolomítico) para uso como corretivo agrícola e essa rocha constitui o pacote sedimentar da Camada Bairrinho, as exposições mais representativas, quase que na sua totalidade, pertencem ao Membro Ipeúna, subunidade do topo da Formação Assistência, e ao seu contato com as formações sobrejacentes Serra Alta, nas porções meridionais e Corumbataí, nas porções setentrionais (Tab. 2). Muito ocasionalmente ocorrem exposições dos membros ou formações inferiores e, ainda assim, em caráter duvidoso. Contudo, as principais ocorrências fósseis, aquelas que podem ser utilizadas para caracterizar as biozonas e que refletem importante influência para o entendimento das questões ambientais dessa unidade, ocorrem justamente nas porções superiores da Formação Assistência, ou seja, o Membro Ipeúna, o que é um fator positivo, não restringindo de forma alguma, o sucesso da presente pesquisa (Fig. 1).

A Camada Bairrinho apresenta em média a espessura de 2,5 metros, variando de 1,5 metros (numa das frentes da Pedreira de Calcário Itapê - Itapetininga / SP) até 4 metros (frente atual da Pedreira de Calcário Bonança - Ipeúna / SP, Fig. 2). Essa camada apresentase com litologia homogênea de calcário dolomítico, de aspecto maciço, com espessura dos estratos da ordem de decímetros ou centímetros, intercalados com lâminas muito finas de folhelho cinza. Essa variação textural é refletida geograficamente, sendo que os paco- tes mais maciços de calcário estão na porção nordeste (e.g. Pedreira de Calcário PH7 - Santa Rosa do Viterbo/ SP) e as porções mais laminadas predominam na porção centro-sudoeste (Pedreira de Calcário Vitti 2 - Rio Claro / SP), como reflexo da situação paleoambiental, ou da paleobatimetria, da época de deposição, uma vez que as porções mais setentrionais, dentro do Estado de São Paulo, constituíam áreas de planícies de marés, em meios hipersalinos (Hachiro 1996).

Sobre a Camada Bairrinho encontra-se depositado um pacote de ritmitos concordante ao banco dolomítico. Da mesma forma que o anterior, possui certa homogeneidade ao longo de toda a faixa de afloramentos, apresentando uma espessura média de 8 metros, embora possa apresentar variações que vão desde uma maior espessura (12 metros na Pedreira de Calcário Itapê - Itapetininga / SP, Fig. 2) até alguns metros ou sua completa ausência, tornando direto o contato da Camada Bairrinho com as formações sobrejacentes (Pedreira de Calcário PH7 - Santa Rosa do Viterbo/SP). Essas mudanças litológicas são, possivelmente, decorrentes do mesmo fator que influenciou as variações da Camada Bairrinho, uma vez que nos ambientes mais costeiros não houve deposição do folhelho ou esse pode ter sido erodido por processos sedimentares de maré e tempestades (Hachiro 1996).

O pacote de ritmitos está dividido em duas por-

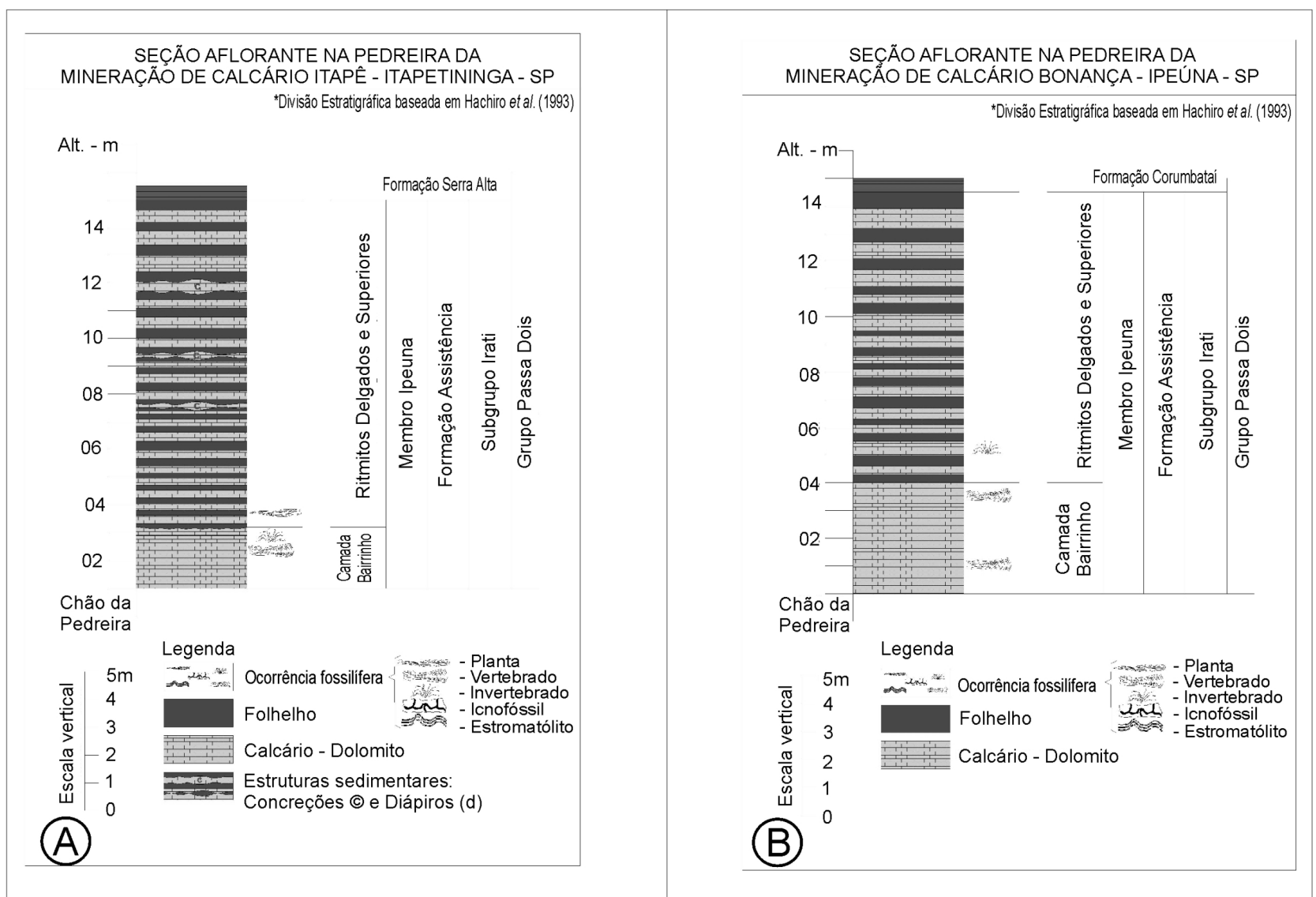

Figura 2 - Coluna estratigráfica da Pedreira Itapê (Itapetininga) (A); Coluna estratigráfica da Pedreira Bonança (Ipeúna) (B). 
ções (Tab. 2), sendo a principal diferença entre ambos a mudança na geometria dos estratos, os quais apresentam-se delgados e tabulares na porção inferior (Ritmitos Delgados) e espessos e deformados na porção superior (Ritmitos Superiores). Nas frentes de lavra, essas características podem ser facilmente observadas, sendo que existe aparente predominância dos ritmitos superiores, que, em termos de espessura total, constituem cerca de $70 \%$ do pacote de ritmitos. Sendo assim e considerando uma exposição média do pacote de ritmitos de 8 metros, evidencia-se que a porção de ritmitos delgados apresenta espessura média de 2 a 3 metros e a de ritmitos superiores cerca de 5 a 6 metros, nas pedreiras visitadas. No presente trabalho, todo o pacote de ritmitos será tratado de forma unificada, uma vez que as assembléias fossilíferas pouco variam dentro desse intervalo, mas a depender da conveniência poderá ser devidamente diferenciado.

Em quase todos os casos, as formações sobrejacentes (Serra Alta e Corumbataí) ocorrem no topo das seções expostas nas pedreiras, apresentando contato concordante com o topo do Membro Ipeúna e compõem pacotes de siltitos ou arenitos finos, raramente maiores que 2 metros de espessura. A coloração, bem como a ausência de carbonatos e de fósseis típicos da unidade subjacente marcam facilmente a separação destas das rochas do Subgrupo Irati. Apenas nas porções do extremo NE paulista (Santa Rosa do Viterbo, Ricardi-Branco et al. 2006), o contato apresenta traços erosivos, típicos daquela situação peculiar, como mencionado anteriormente.

Em todas as visitas de campo foram coletados exemplares fósseis diretamente nas seções de extração. Alguns também foram coletados no pátio de desmonte onde os blocos de rocha eram levados para a moagem. Outros fósseis ainda foram adquiridos por meio de doações, diretamente com o proprietário e/ou funcionários das pedreiras, que os haviam encontrado no momento da extração. Foram coletadas cerca de 90 (noventa) amostras nas pedreiras, compreendendo quatro grupos distintos de fósseis (vegetais, vertebrados, invertebrados e icnofósseis) e dessas amostras, 56 (cinqüenta e seis) exemplares foram selecionados, catalogados e inseridos no Acervo Científico de Paleontologia (CP) do Instituto de Geociências da UNICAMP. A tabela 3 apresenta novas ocorrências com fósseis e sua respectiva posição estratigráfica (segundo Hachiro 1996).

Com relação aos fitofósseis, somente foram encontrados dois lenhos permineralizados (Figs. 3A e 3B), possivelmente relacionados a gimnospermas $(\mathrm{CP} 1 / 1 \mathrm{e}$ CP1/2), sendo um deles associado a folhelhos em Saltinho (na Pedreira de Calcário Diamante) e o outro, às rochas carbonáticas em Itapetininga (na Pedreira de Calcário Itapê). Anteriormente, Mussa (1978a,b, 1980 e 1986a, b) estudou lenhos de Piracicaba e Saltinho, na presente pesquisa foi também registrada a sua presença em Itapetininga (Pedreira de Calcário Itapê).

Os fósseis de vertebrados, mais especificamente

Tabela 3 - Novas ocorrências com fósseis e sua respectiva posição estratigráfica.

\begin{tabular}{|c|c|c|c|c|}
\hline Pedreira & $\begin{array}{l}\text { Localização } \\
\text { (Município) }\end{array}$ & $\begin{array}{l}\text { Latitude Sul } \\
\text { (Dec.) }\end{array}$ & $\begin{array}{l}\text { Longitude Oeste } \\
\text { (Dec.) }\end{array}$ & Fósseis encontrados \\
\hline Itapê & Itapetininga & 23,56619444 & 48,04450000 & Lenho fóssil \\
\hline RochaFértil & Cesário Lange & 23,16591667 & 47,95508333 & Vertebras de mesossaurídeos \\
\hline Cruzeiro & Pereiras & 23,04600000 & 47,92922222 & Mesossaurídeo preservado no folhelho \\
\hline Amaral Machado & Saltinho & 22,88894444 & 47,70441667 & $\begin{array}{l}\text { Mesossaurídeo com estruturas cranianas bem } \\
\text { preservadas }\end{array}$ \\
\hline Bernardino & Saltinho & 22,88405556 & 47,70975000 & Vértebras de mesossaurídeos \\
\hline Diamante & Saltinho & 22,91744444 & 47,75430556 & Lenho fóssil e membros de mesossaurídeos \\
\hline Togran & Tietê & 22,90736111 & 47,75158333 & Vértebras de mesossaurídeos \\
\hline Cinco Estrelas & Angatuba & 23,48158333 & 48,49983333 & Coquinas de carapaças de crustáceos \\
\hline RochaFértil & Cesário Lange & 23,16591667 & 47,95508333 & Coquinas de carapaças de crustáceos \\
\hline Calgi & Saltinho & 22,89902778 & 47,73730556 & $\begin{array}{l}\text { Coquinas de crustáceos com ossos de } \\
\text { mesossaurídeos }\end{array}$ \\
\hline Diamante & Saltinho & 22,91227778 & 47,75300000 & Coquinas de carapaças de crustáceos \\
\hline Togran & Tietê & 22,90736111 & 47,75158333 & Coquinas de carapaças de crustáceos \\
\hline PH7 & $\begin{array}{l}\text { Santa Rosa do } \\
\text { Viterbo }\end{array}$ & 21,49036111 & 47,32116667 & Icnofósseis \\
\hline
\end{tabular}



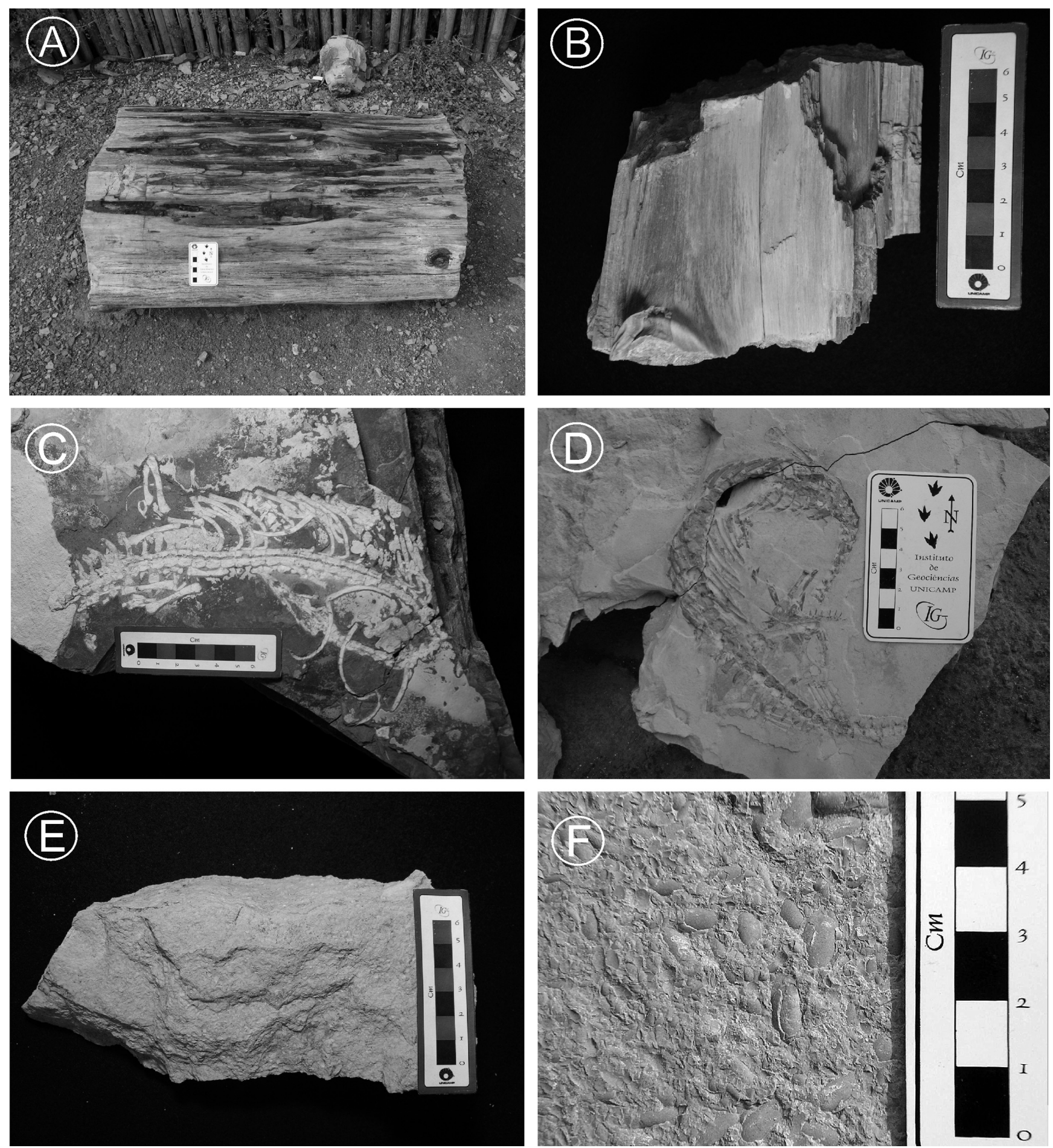

Figura 3 - Exemplares fósseis encontrados na pesquisa. A e B. Lenhos permineralizados (pedreiras Mineração Solo Fértil, Saltinho e Calcário Itapê, Itapetininga), C e D. Esqueletos de mesossaurídeos (pedreiras Amaral Machado, Saltinho e Calcário Itapê, Itapetininga), E. Coquina de crustáceos (pedreira Calcário Vitti, Saltinho) e F. Detalhe das carapaças de crustáceos (pedreira Calcário Cruzeiro, Pereiras).

de mesossaurídeos foram encontrados abundantemente em quase todas as pedreiras visitadas (Figs. 3C e 3D). Como se sabe, esses fósseis constituem importante indício da continuidade dos ambientes sedimentares, sendo também o grupo más utilizado para correlações entre Brasil (Bacia do Paraná) e África (Bacia do Karoo) e em reconstruções paleoambientais do Gondwana Ocidental no Permiano (Oelofsen \& Araujo 1983), juntamente com os fósseis de glossopterídeas Dentro do Subgrupo Irati ocorrem nas três porções do Membro Ipeúna, sendo que os mais basais (encontrados no banco dolomítico) são geralmente classificados na literatura (Barberena \& Timm 2000) como Stereosternum tumidum e os ocorrentes nos pacotes de ritmitos como Mesosaurus brasi- 
liensis. Trabalhos anteriores mencionaram a sua ocorrência em quase todas as pedreiras clássicas (Tab. 3, e.g. Menendez 1976, Massoli 1980, Suguio \& Souza 1985, Mezzalira 1989, 2000, Mezzalira et al. 1986, Hachiro 1996, Vieira et al. 1997). Na presente pesquisa também foram encontrados fósseis nas pedreiras de Cesário Lange (Pedreira RochaFértil); Pereiras (Pedreira Cruzeiro); Saltinho (Pedreiras Amaral Machado, Bernardino e Diamante) e Tietê (Pedreira Togran).

No presente estudo os exemplares mais completos [e.g. espécimes $C P 2 / 21, C P 2 / 22, C P 2 / 23, C P 2 / 27$, $C P 2 / 28, C P 2 / 35$ e $C P 2 / 36$ ] foram coletados nas rochas carbonáticas, ocorrendo com menor freqüência em folhelhos (rochas mais frágeis). Com base nesses exemplares mais completos pôde-se estimar um tamanho médio de $80 \mathrm{~cm}$ para indivíduos, o que corrobora com informações da literatura (Oelofsen \& Araújo 1983). Vale destacar a boa preservação dos espécimes de Cesário Lange (Pedreira RochaFértil), Itapetininga (Pedreira Itapê) e Saltinho (Pedreiras Amaral Machado e Diamante), que apresentam fósseis geralmente articulados com coluna e membros conectados, e a grande abundância de fragmentos de ossos, chegando a formar bone beds na Pedreira PH7 em Santa Rosa de Viterbo.

Com relação aos invertebrados, foram coletadas coquinas compostas exclusivamente por somitos de crustáceos sempre desarticulados (Figs. 3E e 3F), em Angatuba (Pedreira Cinco Estrelas), Cesário Lange (Pedreira RochaFértil), Itapetininga (Pedreira Itapê), Ipeúna (Pedreira Bonança), Limeira (Pedreira Cruzeiro), Pereiras (Pedreira Cruzeiro), Saltinho (Pedreiras Calgi, Bernardino, Diamante e Amaral Machado) e Tietê (Pedreira Togran). Em linhas gerais, as coquinas de crustáceos ocorrem em níveis contínuos próximos ou exatamente no topo do banco dolomítico (Liocaris Vieira et al. 1991). Também foram coletadas coquinas com abundantes carapaças desarticuladas de crustáceos no pacote de ritmitos, recebendo a denominação de Paulocaris (Mezzalira 1971, 1980), as quais aparecem sempre associadas a fragmentos ósseos de mesossaurídeos (e.g. exemplares da Pedreira de Calcário Calgi, Saltinho). Hachiro (1996), mencionou que essas concentrações de carapaças de crustáceos seriam conseqüência de retrabalhamento por ondas de tempestade, gerando os conhecidos tempestitos (e.g. exemplares da Pedreira de Calcário Cruzeiro, Limeira).

Por último, com relação aos icnofósseis, foram observadas marcas de locomoção de invertebrados, de dimensões centimétricas, possivelmente relacionadas com tubos de artrópodes filtradores na base dos estro- matólitos na Pedreira de Calcário PH7, em Santa Rosa do Viterbo (Ricardi-Branco et al. 2006). Anteriormente icnofósseis foram descritos na Região de Piracicaba e Limeira (e.g. Kegel 1967). Dentro desse grupo podem também ser incluídos os estromatólitos gigantes da Pedreira PH7, em Santa Rosa do Viterbo anteriormente mencionados por Sugio \& Souza (1985), Mello e Sousa (1985) e Ricardi-Branco et al. (2006).

CONCLUSÕES Por meio do estudo puderam ser concebidas as seguintes conclusões:

Para o Estado de São Paulo, área de estudo do presente trabalho, a hierarquização estratigráfica proposta por Hachiro et al. (1993) é válida e funcional, sendo que os pacotes e camadas do Subgrupo Irati podem ser reconhecidos em campo, incluindo as assembléias fossilíferas, em especial aquelas do Membro Ipeúna (vegetais, mesossaurídeos, crustáceos e estromatólitos).

As ocorrências fossilíferas têm considerável abundância, sendo encontrados exemplares tanto nas pedreiras clássicas (já descritas), quanto nas novas frentes de lavra aqui estudadas. As ocorrências nas novas áreas de extração, corroboram com a conceituação geral das sistemáticas de biozoneamento e, via de regra, têm ocorrido em conformidade com as ocorrências clássicas, documentadas na literatura científica.

A demanda pela atividade de extração mineral, impulsionada pela demanda agrícola e industrial, tem proporcionado avanços notáveis na abertura de novas frentes de lavra de calcário e, por conseguinte, oferecido novas oportunidades para a descoberta de fósseis, propiciando um contínuo aperfeiçoamento das pesquisas acerca do Subgrupo Irati.

Agradecimentos Os autores agradecem à Fundação de Amparo à pesquisa do estado de São Paulo (FAPESP) pelo apoio financeiro concedido por meio do projeto de Iniciação Científica $n^{\circ}$ 03/07849-0 e o projeto de $\mathrm{Au}$ xílio à Pesquisa Processo 03/07031-7 "Informatização do acervo didático de paleontologia e confecção de um mapa interativo para as pedreiras do Grupo Passa Dois no estado de São Paulo". Agradecem também, às empresas mineradoras de calcário do Estado de São Paulo por abrir suas frentes de lavra para a pesquisa, aos avaliadores do trabalho da Revista Brasileira de Geociências e aos pesquisadores e colaboradores do Instituto de Geociências da Universidade Estadual de Campinas (UNICAMP) que ajudaram no fornecimento de informações e no suporte técnico para esta pesquisa.

\section{Referências}

Barberena D.C.A. \& Timm L.L. 2000. Características dos mesosaurus e suas adaptações ao meio aquático. In: Holz M. \& Ross L.F. (eds.) Paleontologia do Rio Grande do Sul. Porto Alegre, UFRGS/CIGO, p. 194-209.

Carvalho I.S. (ed.) 2000. Paleontologia. Rio de Janeiro, Ed. Interciência, $628 \mathrm{p}$.
DEPARTAMENTO DE ESTRADAS DE RODAGEM DO ESTADO DE SÃO PAULO (DER-SP). 2004. Mapa rodoviário do estado de São Paulo. Disponível em: www. der. sp.gov.br. Acessado em 12/2004.

DEPARTAMENTO NACIONAL DE PRODUÇÃO MINERAL (DNPM). 2005. Cadastro Mineiro. Disponível em: 
www.dnpm.gov.br. Acesso em 08/2005.

Hachiro J. 1991. Litotipos, associações faciológicas e sistemas deposicionais da Formação Irati no estado de São Paulo. Dissertação de Mestrado, Instituto de Geociências, Universidade de São Paulo, 175p.

Hachiro J. 1996. O Subgrupo Irati (Neopermiano) da Bacia do Paraná. Tese de Doutoramento, Instituto de Geociências, Universidade de São Paulo, 196p.

Hachiro J., Coimbra A.M., Matos S.L.F. 1993. O Caráter cronoestratigráfico da Unidade Irati. In: SBG, Simpósio sobre Cronoestratigrafia da Bacia do Paraná, 1, Resumos, IG-UNESP, p. 62-63.

Kegel W. 1967. Rastros do grupo dos bilobites da Formação Irati. São Paulo, DNPM/DGM. Notas preliminares. Ests. 136, 9 p.

Mello e Souza S.H.M. 1985. Fácies sedimentares das formações Estrada Nova e Corumbataí no estado de São Paulo. Dissertação de Mestrado, Instituto de Geociências, Universidade de São Paulo, 142p.

Menendez C.A. 1976. Contenido palinológico de estratos permicos con "Mesosaurus" de Rio Claro, São Paulo, Brasil. Inst. Nac. Invest. Cienc. Naturales, 2:1-30.

Mezzalira S. 1971. Contribuição ao conhecimento da geologia de subsuperfície e da paleontologia da Formação Irati, no estado de São Paulo. In: SBP, Simpósio de Paleontologia, Rio de Janeiro, Anais da Academia Brasileira de Ciências, 43 (Suplemento), p. 273-336.

Mezzalira S. 1980. Bioestratigrafia do Grupo Passa Dois no estado de São Paulo. Revista IG, 1:15-34.

Mezzalira S, Maranhão M.S.A.S., Vieira P. 1986. Bibliografia analítica da Paleontologia do estado de São Paulo. SMA. Instituto Geológico. Boletim, 8:1-235.

Mezzalira S. 1989. Os fósseis do estado de São Paulo. SMA. Instituto Geológico, $141 \mathrm{p}$.

Mezzalira S. 2000. Os fósseis do estado de São Paulo, Parte II. Período 1987 (parcial) - 1996. SMA. Instituto Geológico, Boletim, 15:1-70.

Mussa D. 1978 a. On the anatomy of wood showing affinities with the genus Vertebraria Royle, from the Irati Formation, State of São Paulo. Boletim IG - USP, 9:153-201

Mussa D. 1978b. Brasilestixylon e Solenobrasilioxylon, dois novos gêneros gondwânicos na Formação Irati, estado de São Paulo, Brasil. Boletim IG - USP, 9:118-127.

Mussa D. 1980. Ocorrência do gênero Antarticoxylon Seward na Fprmação Irati (Permiano), estado de São Paulo, Brasil. In: Congreso Argentino de Paleontología y Estratigrafía, 2 y Congreso Latinoamericano de Paleontología, 1, Actas, 4, p. 139-155.

Mussa D. 1986a. As formas gondwânicas do Grupo Solenóide e sua distribuição estratigráfica. Anais da Academia Brasileira de Ciências, 58:61-87

Mussa D. 1986b. As formas taxóides, abietóides e phyllocladóides do Gondwana e as desmembradas do gênero Complexo Dadoxylon Endl. Anais da Academia Brasileira de Ciências, 58:169-170

Oelofsen B.W. \& Araújo D.C. 1983. Palaeocological implications of the distribution of Mesosaurid reptiles in the Permian Irati Sea (Parana Basin), South America. Revista Brasileira de Geociências, 1:1-6.

Ricardi-Branco F., Caíres E.T., Silva A.M. 2006. Campo de Estromatólitos Gigantes de Santa Rosa de Viterbo, SP. Um excelente registro do litoral do mar Irati, Permiano, Bacia do Paraná, Brasil. In: Winge M., Schobbenhaus C., Berbert-Born M., Queiroz E.T., Campos D.A., Souza C.R.G., Fernandes A.C.S. (eds.) Sitios Geológicos e Paleontológicos do Brasil. Disponível em: http://www.unb. br/ig/sigep/sítio 125.pdf. Acessado em 24/11/2006.

SERVIÇO GEOLÓGICO DO BRASIL. 2005. Bases Geológicas \& Carta Geológica do Brasil ao Milionésimo. Disponível em: www.cprm.gov.br. Acessado em Junho de 2005.

Suguio K. \& Sousa S.H.M. 1985. Restos de mesossaurídeos na Formação Corumbataí, Permiano da Bacia do Paraná, no estado de São Paulo. Anais da Academia Brasileira de Ciências, 57:339-347.

Vieira P.C., Mezzalira S., Ferreira F.J.F. 1991. Mesossaurídeo (Stereosternum Tumidum) e crustáceo (Liocaris Huenei) no Membro Assistência da Formação Irati (P) nos municípios de Jataí e Montevidiu, estado de Goiás. Revista Brasileira de Geociências, 21:224-235.

Vieira P.C., Mezzalira S., Sousa P.A. 1997. Bibliografia analítica da Paleontologia do estado de São Paulo. Parte II. Período 1987 - 1996. SMA. IG, Boletim, 14:1-207.

Manuscrito ID 8300 Submetido em 11 de julho de 2007 Aceito em 10 de junho de 2008 Sistema eletrônico de submissão 